\title{
Pork-Barrel Politics and Polarization
}

\author{
Aaron Hedlund
}

This article explores how earmarks shape the ideological composition of elected officials in Congress. Relative to the classic median voter theorem, the framework developed here introduces multiple legislative districts and incorporates a desire for local earmarks in the specification of voter preferences. The main theoretical result demonstrates that competition among politicians to "bring home the bacon" substantially reduces Congressional polarization. Data from after the earmark ban of 2011 provide supporting evidence for this mechanism. (JEL D72, E62, D78, H41)

Federal Reserve Bank of St. Louis Review, First Quarter 2019, 101(1), pp. 57-68. https://doi.org/10.20955/r.101.57-68

\section{INTRODUCTION}

Casual observation and an abundance of research reveal a trend of growing political polarization in the United States over the past few decades. $\frac{1}{}$ To some observers, polarization impedes effective governance and poses a risk to economic performance. In support of this view, Mian, Sufi, and Trebbi (2014) provide evidence from a large sample of countries showing that, following a financial crisis, heightened ideological polarization weakens ruling coalitions and creates legislative gridlock that hampers reform efforts. In addition, Baker et al. (2014) attribute a rise in U.S. policy uncertainty to political polarization and Azzimonti (2018) links higher partisan conflict to depressed investment. By showing that causality also runs in the opposite direction, Algan et al. (2018) raise the specter of a feedback loop between poor economic performance and polarization that gets worse over time. Searching for potential causes, voices from across the political spectrum-including President Trump himself-have attributed some of the partisan rancor to the 2011 federal earmark ban that remains in place. $\stackrel{2}{\text { After all, }}$ the number of bills passed into law immediately following the moratorium dropped to its lowest level in 20 years. $\underline{3}$

Aaron Hedlund is an assistant professor of economics at the University of Missouri-Columbia and a visiting scholar at the Federal Reserve Bank of St. Louis. The author thanks two referees for their useful feedback.

(9) 2019, Federal Reserve Bank of St. Louis. The views expressed in this article are those of the author(s) and do not necessarily reflect the views of the Federal Reserve System, the Board of Governors, or the regional Federal Reserve Banks. Articles may be reprinted, reproduced, published, distributed, displayed, and transmitted in their entirety if copyright notice, author name(s), and full citation are included. Abstracts, synopses, and other derivative works may be made only with prior written permission of the Federal Reserve Bank of St. Louis. 
Figure 1

Evidence of Rising Voter Polarization Over the Past Two Decades
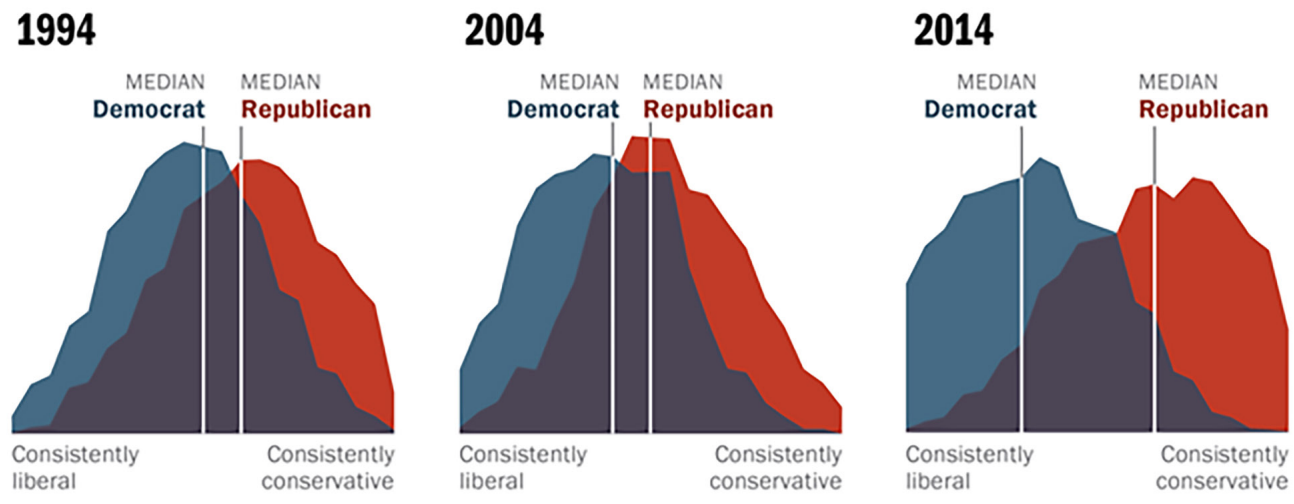

NOTE: Ideological consistency based on a scale of 10 political values questions (see Appendix A in the source). The blue area in this chart represents the ideological distribution of Democrats and the red area of Republicans. The overlap of these two distributions is shaded purple. Republicans include Republican-leaning independents: Democrats include Democratic-leaning independents (see Appendix B in the source).

SOURCE: Pew Internet \& American Life Project (2014).

Ironically, there are also polarized views on the consequences and desirability of polarization itself. While some lament a decline in legislative accomplishments, others praise the reduction in political horse trading and spending on "pet projects," such as the controversial \$400 million "Bridge to Nowhere" in Alaska that lawmakers eventually scuttled after the ensuing public uproar. ${ }^{4}$ For better or worse, the earmark ban has undoubtedly removed one of the major sources of leverage Congressional leadership can use to enforce party disciplineas described in Grossman and Helpman (2005) — thus paving the way for ideology to play a greater role in the political process.

Putting aside any normative concerns, this article analyzes the link between pork-barrel spending (equivalently, earmarks) — defined as appropriations secured for the express purpose of bringing money to a legislator's local district-and Congressional polarization. Theoretically, I consider an environment with multiple districts where voters have a preference both for ideological compatibility with their elected legislator and for greater earmark spending in their district. Once elected, legislators who are closer to the ideological mean of Congress receive a greater share of pork-barrel funding, regardless of the overall distribution of voter ideologies. The median voter in each district - who is effectively in the position of kingmakerbalances ideology with the ability to "bring home the bacon" when selecting his or her preferred political candidate, taking as given what happens elsewhere. I characterize the equilibrium and show that earmarks significantly compress the ideological distribution of Congress relative to that of the population. Empirically, evidence from after the 2011 earmark ban supports these theoretical findings. 


\section{Figure 2}

\section{Partisan DW-NOMINATE Spread (Left); Federal Reserve Bank of Philadelphia Partisan Conflict Index (Middle); and Change in the Shor-McCarty State Polarization Index (Right)}
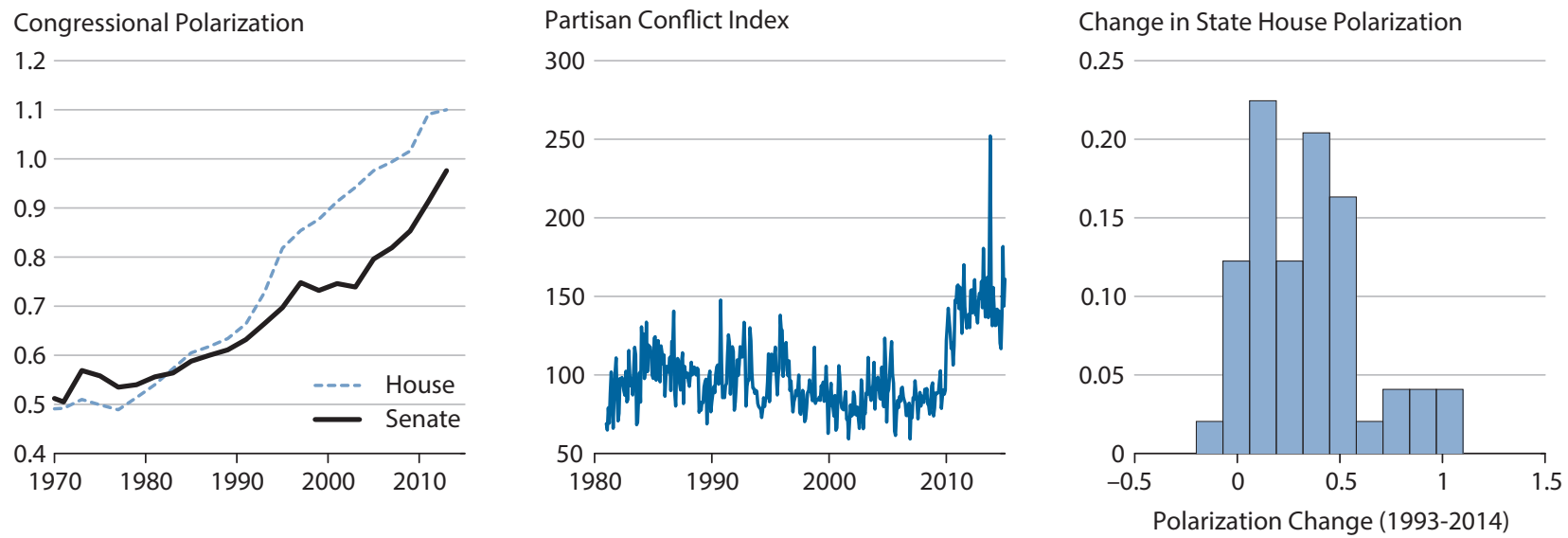

\section{EMPIRICAL TRENDS}

A recent Pew Research study by Dimock et al. (2014) documents the increasing polarization of the American electorate. As seen in Figure 1, the amount of overlap between Democratic and Republican voters has fallen dramatically since the mid-1990s. Back in 1994, 36 percent of Republicans were to the political left of the median Democrat, and 30 percent of Democrats were to the right of the median Republican. In 2004, those measures of ideological overlap fell to 8 percent and 6 percent, respectively. Furthermore, the data show that polarization has accelerated over the past decade.

This heightened polarization has also crossed over into legislatures. Figure 2 shows the time series for DW-NOMINATE, which is a commonly used index of polarization developed by Poole and Rosenthal (1984) based on Congressional voting records. .5 At the federal level, the left panel shows that ideological polarization has increased in both the U.S. House and Senate, with a notable acceleration over the past 15 years. Based on the work of Azzimonti (2018), the Federal Reserve Bank of Philadelphia maintains a measure of U.S. political disagreement called the Partisan Conflict Index, which exhibits a notable rise starting in the late 2000s (middle panel). State legislatures have not been immune to these political winds either. Using data from the Vote Smart Political Courage Test (formerly the Project Vote Smart National Political Awareness Test), Shor and McCarty (2011) develop a state-level index of polarization. The right panel of Figure 2 plots the histogram of changes in this index across the states between 1993 and 2014; in the overwhelming majority of states, polarization has increased. Using a different methodology, Andris et al. (2015) show that partisan division has increased in the U.S. Congress while cross-party collaboration has fallen. Figure 3 gives a visual representation of these striking trends. 


\section{Hedlund}

\section{Figure 3}

\section{Partisan Division in the U.S. Congress}
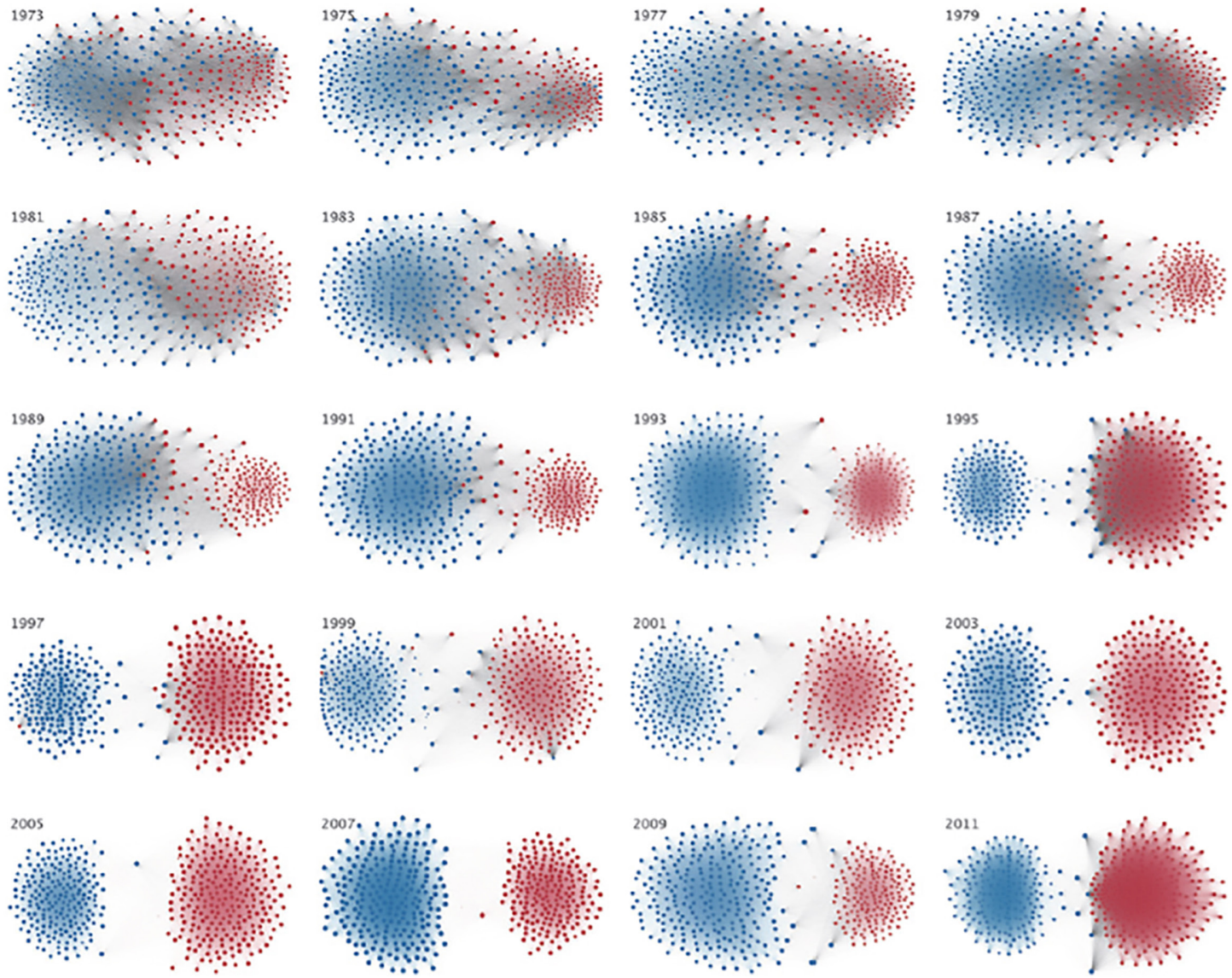

NOTE: Each dot represents a member of the U.S. House of Representatives, with Republicans in red and Democrats in blue. Edges are drawn between individuals of either party who agree with each other on roll-call votes at least as often as two generic members sharing a party label. SOURCE: Andris et al. (2015).

As polarization has gone up, measures of federal legislative productivity have fallen, whether for better or worse. As documented in the left panel of Figure 4, the number of bills passed by the U.S. Senate has exhibited a downward trend since the 1970s, and McCarty (2016) shows that legislative delays for appropriations bills have risen substantially. McCarty (2016) also runs counterfactuals and predicts that, had polarization remained constant, the passage of Mayhew laws - a measure of landmark legislation - would have been considerably higher over the past 20 years. In each of these cases, the decline in legislative productivity appears to have accelerated in the late 2000s.

In fact, from the mid-1990s to the mid-2000s, legislative productivity actually temporarily stabilized. According to data from the organization Citizens Against Government Waste (CAGW) shown in Figure 4, spending on earmark projects escalated dramatically during 


\section{Figure 4}

\section{Number of Bills Passed by the U.S. Senate (Left), CAGW Measure of Earmark Project Count (Middle), and CAGW Measure of Earmark Spending (Right)}
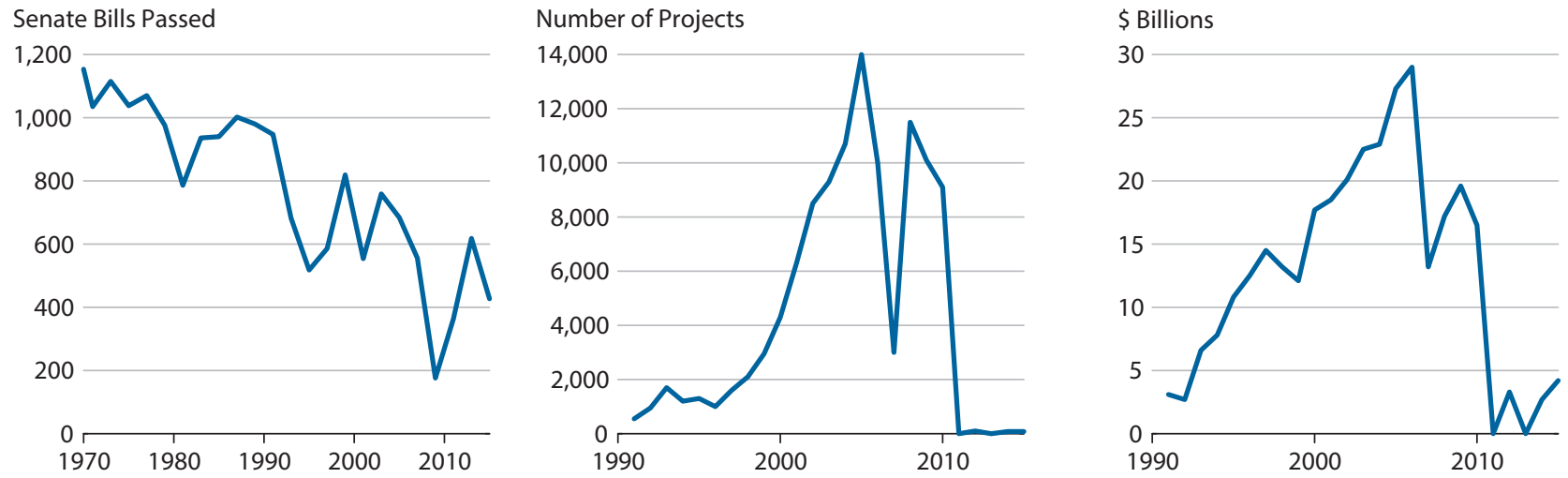

SOURCE: The middle and right panels are from the CAGW, and the first panel is from the Brookings Institution's "Vital Statistics on Congress."

this interlude. $\underline{6}$ However, in response to voter backlash, Congress eventually instituted a oneyear moratorium on earmarks in 2007 followed by a ban in 2011 that remains in effect today.

The next section formalizes a model where competition over pet-project funding moderates the ideological distribution of elected officials relative to the voter population. However, if voter preferences change over time in a way that places more weight on ideology over elected officials' ability to "bring home the bacon," earmarks lose their salience and legislative polarization rises. In this sense, the outcry over earmarks and subsequent ban is a natural consequence of more ideological voting.

\section{THE MODEL}

Consider an environment with $n$ legislative districts, $\{1,2, \ldots, n\}$, where the median voter in district $i$ has ideology $\mu_{i} \in[0,1]$ in a one-dimensional issue space. As in the classic median voter theorem, voters care about how closely the ideology of their elected official, $x_{i}$, aligns with their own views. However, voters also value earmarks spent in their district, $t_{i}$. I assume that $t_{i}$ is the net transfer to district $i$, which implies that $t_{i}$ may be either positive or negative. Voter preferences over ideology and pork-barrel funds are given by

$$
U\left(x_{i}, t_{i} ; \mu_{i}\right)=\beta t_{i}-(1-\beta)\left(x_{i}-\mu_{i}\right)^{2},
$$

where $\beta \in[0,1]$ is the relative weight placed on earmarks.

\subsection{Competition for Earmarks}

After an election, earmarks are awarded disproportionately to elected officials who are closest to the unweighted ideological mean of the legislature, $\bar{x}$, regardless of the allocation 
of voters to legislative districts. ${ }^{7}$ For example, in the U.S. federal government, the population of each state impacts its representation in the House but not in the Senate. In addition, I impose two other restrictions on earmarks. First, because earmarks are the net fiscal transfer to each district, they must sum to zero; that is, $\sum_{i} t_{i}\left(\left\{x_{j}\right\}_{j=1}^{n}\right)=0$. Second, I assume that identical districts are treated identically; that is, $t_{i}\left(x_{i}, \mathbf{x}_{-i} ; \bar{x}\right)=t_{j}\left(x_{j}, \mathbf{x}_{-j} ; \bar{x}\right)$ whenever $x_{i}=x_{j}$, where $\mathbf{x}_{-i} \equiv\left\{x_{k}\right\}_{k \neq i}$. To be concrete, I assume the following function:

$$
t_{i}(\mathbf{x} ; \bar{x})=\frac{1}{n-1} \sum_{j \neq i}\left(x_{j}-\bar{x}\right)^{2}-\left(x_{i}-\bar{x}\right)^{2},
$$

where the coefficient $\frac{1}{n-1}$ ensures that net transfers sum to zero. $\frac{8}{}$

Intuitively, this formula states that legislators who deviate substantially from the average position of their colleagues receive fewer pork-barrel funds, perhaps because they have less influence or do not "go along to get along." To reiterate, this arrangement stands in contrast to one in which legislators are punished for straying from the mainstream of voters. Here, a conservative (liberal) Congress would not punish members simply for sitting ideologically to the right (left) of the population at large.

\subsection{Election Outcomes}

Given $k_{i}$ candidates, the median voter in district $i$ chooses his or her preferred candidatewho ends up being the winner-by solving

$$
\max _{x_{i} \in\left\{x_{i}^{1}, x_{i}^{2}, \ldots, x_{i}^{\left.k_{i}\right\}}\right\}} U\left(x_{i}, t_{i}\left(x_{i}, \mathbf{x}_{-i} ; \bar{x}\right) ; \mu_{i}\right) .
$$

In words, the median voter chooses the candidate that offers the best combination of ideological compatibility and ability to attract earmarks, as determined by the transfer function $t_{i}$. Note that, in general, the presence of a finite number of candidates makes this problem discrete and not amenable to solving with first-order conditions. However, if candidates are first able to choose their position and care only about winning, then in a subgame perfect equilibrium, the winner stakes his or her ideological claim exactly where the median voter's first-order condition is satisfied.

\section{RESULTS}

This section solves for the electoral equilibrium and analyzes how earmarks affect the ideological composition of Congress. For generic $U_{i}\left(x_{i}, t_{i} ; \mu_{i}\right)$ and $t_{i}(\mathbf{x} ; \bar{x})$, the first-order condition of the median voter is

$$
0=\frac{\partial U}{\partial x_{i}}+\frac{\partial U}{\partial t_{i}}\left(\frac{\partial t_{i}}{\partial x_{i}}+\frac{1}{n} \frac{\partial t_{i}}{\partial \bar{x}}\right)
$$


The first term represents the direct marginal contribution of $x_{i}$ to utility, and the second term reflects the indirect effect of $x_{i}$ on utility as transfers respond to the shifting gap between $x_{i}$ and the legislator mean $\bar{x}$, which itself changes by a factor of $1 / n$ to any movements in $x_{i}$.

For specific functions (1) and (2), the terms in (4) become

$$
\begin{aligned}
& \frac{\partial U}{\partial x_{i}}=-2(1-\beta)\left(x_{i}-\mu_{i}\right) \\
& \frac{\partial U}{\partial t_{i}}=\beta \\
& \frac{\partial t_{i}}{\partial x_{i}}=-2\left(x_{i}-\bar{x}\right) \\
& \frac{\partial t_{i}}{\partial \bar{x}}=\frac{-2 \sum_{j \neq i} x_{j}}{n-1}+2 x_{i} .
\end{aligned}
$$

Substituting these terms into (4) gives the final first-order condition,

$$
0=-2(1-\beta)\left(x_{i}-\mu_{i}\right)+\beta\left\{-2\left(x_{i}-\bar{x}\right)+\frac{1}{n}\left[\frac{-2 \sum_{j \neq i} x_{j}}{n-1}+2 x_{i}\right]\right\} \text {. }
$$

A bit of algebra gives the ideological position of the winner in district $i$ :

$$
x_{i}=\left(\frac{1-\beta}{1-\beta+\beta\left(\frac{n-2}{n}\right)}\right) \mu_{i}+\left(\frac{\beta\left(\frac{n-2}{n}\right)}{1-\beta+\beta\left(\frac{n-2}{n}\right)}\right) \overline{x_{-i}},
$$

where $\overline{x_{-i}}$ is the ideological average of the elected officials outside district $i$.

Note that $x_{i}=\mu_{i}$ if voters care only about ideology (i.e., $\beta=0$ ), as one would expect. Similarly, if voters only value earmarks, then $x_{i}=\overline{x_{-i}}$. Therefore, pork-barrel spending causes the elected official from district $i$ to have an ideology in between that of the median voter in district $i$ and the average of the other legislators. Before discussing the Nash equilibrium in Section 4.2 , the analysis can be simplified by examining the limiting case with infinitely many legislative districts.

\section{1 Limit Analysis}

As $n \rightarrow \infty$, the median voter's choice of winning candidate simplifies to

$$
x_{i}=(1-\beta) \mu_{i}+\beta \bar{x},
$$

where $\overline{x_{-i}}=\bar{x}$ in the limit.

From this equation, the legislator mean $\bar{x}$ must satisfy

$$
\bar{x}=(1-\beta) \bar{\mu}+\beta \bar{x},
$$


which readily implies that $\bar{x}=\bar{\mu}$. Therefore, legislator ideology in district $i$ is

$$
x_{i}=(1-\beta) \mu_{i}+\beta \bar{\mu} \text {. }
$$

In words, the ideology of district $i$ 's elected official is a weighted average of the median voter in district $i$ and the average of median voters across all of the districts. Thus, while porkbarrel spending has no impact on average legislator ideology, Theorem 1 shows that it reduces ideological variance relative to the population.

Theorem 1. (Earmarks Reduce Partisanship) A preference for pork-barrel spending-that is, $\beta>0$-reduces ideological variance in Congress:

$$
\frac{\operatorname{var}(x)}{\operatorname{var}(\mu)}=(1-\beta)^{2}<1 .
$$

Proof. The result follows directly from equation (7).

Intuitively, the stronger a preference voters have for earmarks, the more they have to ensure that their elected representative is aligned with the ideology of all the other representatives. With this motive acting symmetrically in every district, the result is a mean-preserving compression of the ideological distribution in the legislature.

\subsection{The Finite Case}

With a finite number of legislative districts, the election outcome is determined by the static Nash equilibrium of the game where each of the $n$ median voters selects his or her preferred candidate according to equation (4), taking as given what occurs in all other districts. Mathematically, the vector of legislator ideologies $\mathbf{x}$ solves the following system of equations:

$$
\left[\begin{array}{c}
x_{1} \\
x_{2} \\
\vdots \\
x_{n}
\end{array}\right]=(1-\alpha(n))\left[\begin{array}{c}
\mu_{1} \\
\mu_{2} \\
\vdots \\
\mu_{n}
\end{array}\right]+\alpha(n)\left[\begin{array}{c}
\frac{1}{n-1} \sum_{j \neq 1} x_{j} \\
\frac{1}{n-1} \sum_{j \neq 2} x_{j} \\
\vdots \\
\frac{1}{n-1} \sum_{j \neq n} x_{j}
\end{array}\right],
$$

where $1-\alpha(n)$ is the coefficient on $\mu_{i}$ in equation (5). Theorem 2 explicitly solves for the equilibrium given arbitrary $n$.

Theorem 2. (Electoral Equilibrium) The equilibrium vector of legislator ideologies is given by

$$
\mathbf{x}=(1-\theta) \mu+\frac{\theta}{n-1}(\mathbf{P}-\mathbf{I}) \mu,
$$


where $\theta=\frac{(n-1) \alpha(n)}{n-1+\alpha(n)}=\frac{\beta(n-2)(n-1)}{n(n-1-\beta)}, \mathbf{P}$ is an $n \times n$ matrix of ones, and $\mathbf{I}$ is the $n \times n$ identity matrix.

Proof. The expression (9) can be written in matrix form as

$$
\mathbf{x}=(1-\alpha(n)) \mu+\left(\frac{\alpha(n)}{n-1}\right)(\mathbf{P}-\mathbf{I}) \mathbf{x} .
$$

Collecting all the $\mathbf{x}$ terms gives

$$
\left[\frac{-\alpha(n)}{n-1} \mathbf{P}+\left(1+\frac{\alpha(n)}{n-1}\right) \mathbf{I}\right] \mathbf{x}=(1-\alpha(n)) \mu,
$$

which after some algebra is equivalent to

$$
[b \mathbf{P}+(a-b) \mathbf{I}] \mathbf{x}=(n-1)(1-\alpha(n)) \mu,
$$

where $b=-\alpha(n)$ and $a=n-1$.

Inverting the matrix on the left gives the equilibrium legislator ideologies,

$$
\mathbf{x}=[b \mathbf{P}+(a-b) \mathbf{I}]^{-1}(n-1)(1-\alpha(n)) \mu,
$$

where it can be shown that

$$
[b \mathbf{P}+(a-b) \mathbf{I}]^{-1}=\frac{-b}{(a-b)(n b+a-b)} \mathbf{P}+\frac{1}{a-b} \mathbf{I} .
$$

Substituting this expression into the previous equation gives

$$
\mathbf{x}=\left[\frac{\alpha(n)}{n-1+\alpha(n)} \mathbf{P}+\frac{(n-1)(1-\alpha(n))}{n-1+\alpha(n)} \mathbf{I}\right] \mu .
$$

Lastly, defining $\theta=\frac{(n-1) \alpha(n)}{n-1+\alpha(n)}$ and doing some algebra completes the proof.

The scalar representation of equation (10) makes it clear that the ideology of each legislator is the convex combination of the ideology of the median voter in his or her district and the average of the ideologies of the median voters everywhere else:

$$
x_{i}=(1-\theta) \mu_{i}+\theta \overline{\mu_{-i}} \text {. }
$$

\subsection{A Numerical Example}

To provide further intuition, I simulate some numerical examples with $n=435$ legislative districts, just as in the U.S. House of Representatives. Figure 5 shows different scenarios for the equilibrium ideological distribution of Congress compared with that of voters. In the top 
Hedlund

\section{Figure 5}

Earmark Preferences with Weight $\beta=0.33$ (Left Column) and Weight $\beta=0.67$ (Right Column)
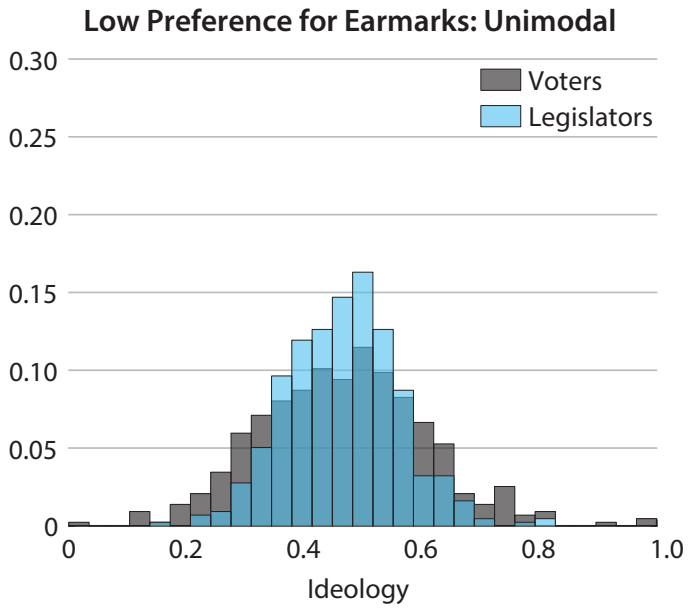

Low Preference for Earmarks: Bimodal
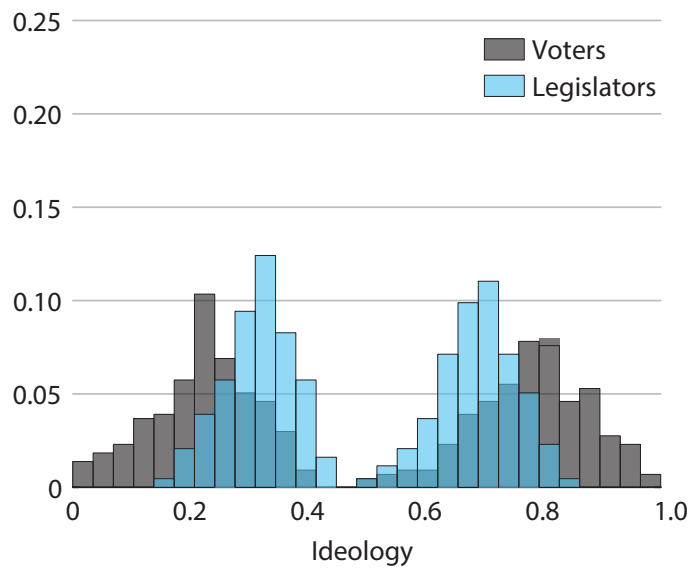

High Preference for Earmarks: Unimodal

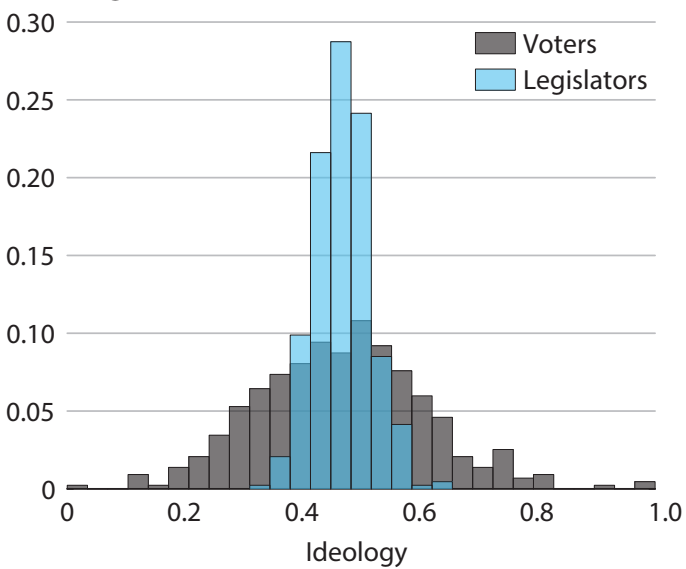

High Preference for Earmarks: Bimodal

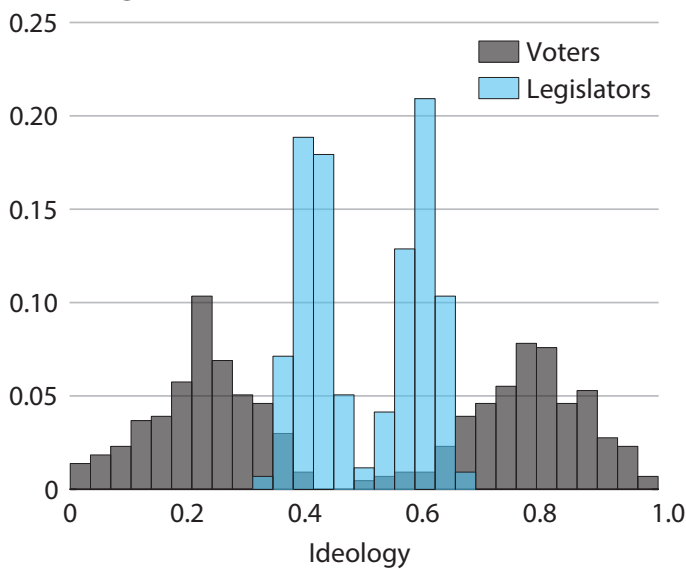

row, I randomly draw voter ideologies from a truncated normal distribution and compute the electoral equilibrium. In the top-left panel, I consider the case where voters place a relatively low weight on earmarks, $\beta=0.33$. Even in this scenario, the presence of earmarks compresses the ideological distribution of Congress. In the top-right panel, I increase the weight to $\beta=0.67$, which markedly squeezes the Congressional ideological distribution still further. In the bottom panels, I repeat the exercise for a bimodal voter distribution and similar lessons emerge.

\section{CONCLUSIONS}

By creating competition for local funds between legislators in different districts, the process for earmarking partially replaces the role of ideology in policymaking with a "bring home 
the bacon" motive, thereby reducing polarization in Congress, whether for better or worse. However, there are several issues I abstract from in this analysis-particularly regarding the details of political institutions - that preclude making any immediate policy recommendations. For example, the presence of two dominant parties possessing well-established institutional power may produce different outcomes than would a parliamentary system in which numerous small parties continuously jockey for control. I leave this issue and others for future work.

\section{NOTES}

1 For example, see Boxell, Gentzkow, and Shapiro (2017); Gentzkow, Shapiro, and Taddy (2017); Autor et al. (2017); and Martin and Yurukoglu (2017).

2 President Trump has stated the following (DeBonis, 2018): “And I hear so much about earmarks, the old earmark system, how there was a great friendliness when you had earmarks...In the old days of earmarks...they went out to dinner at night, and they all got along, and they passed bills. That was an earmark system. And maybe we should think about it."

$\underline{3}$ A deeper analysis is required to determine whether this correlation represents causation.

4 For more information on the "Bridge to Nowhere" debate, see https://www.washingtontimes.com/news/2015/nov/8/alaska-kills-bridge-to-nowhere-that-helped-put-end/.

$\underline{5}$ Technical details can be found in this book: https://www.cambridge.org/catalogue/catalogue.asp?isbn=9780521617475.

6 CAGW deems a piece of legislation pork-barrel spending if it meets at least two of the following seven criteria: (i) requested by only one chamber of Congress; (ii) not specifically authorized; (iii) not competitively awarded; (iv) not requested by the president; (v) greatly exceeds the president's budget request or the previous year's funding; (vi) not the subject of Congressional hearings; and (vii) serves only a local or special interest.

$\underline{7}$ This assumption is consistent with a wide body of theoretical and empirical work summarized in Alexander, Berry, and Howell (2016).

8 An equivalent formulation of the earmark function is $t_{i}(\mathbf{x} ; \bar{x})=\operatorname{var}(\mathbf{x})-\frac{n}{n-1}(x(i)-\bar{x})^{2}$. None of the results change if transfers sum to a constant other than zero. It is also possible that earmarks could create positive aggregate spillovers, for example, by financing productive investment, but it is unclear to what extent voters internalize them when voting and, thus, how much the results might change.

\section{REFERENCES}

Alexander, Dan; Berry, Christopher R. and Howell, William G. "Distributive Politics and Legislator Ideology." Journal of Politics, 2016, 78(1), pp. 214-31; https://doi.org/10.1086/683643.

Algan, Yann; Guriev, Sergei; Papaioannou, Elias and Passari, Evgenia. "The European Trust Crisis and the Rise of Populism." Working paper, 2018.

Andris, Clio; Lee, David; Hamilton, Marcus J.; Martino, Mauro; Gunning, Christian E. and Selden, John Armistead. "The Rise of Partisanship and Super-Cooperators in the U.S. House of Representatives." PLoS ONE, 2015, 10(4); https://doi.org/10.1371/journal.pone.0123507.

Autor, David; Dorn, David; Hanson, Gordon and Majlesi, Kaveh. "Importing Political Polarization? The Electoral Consequences of Rising Trade Exposure." Working paper, 2017.

Azzimonti, Marina. "Partisan Conflict and Private Investment." Journal of Monetary Economics, 2018, 23; https://doi.org/10.1016/j.jmoneco.2017.10.007. 


\section{Hedlund}

Baker, Scott R.; Bloom, Nicholas; Canes-Wrone, Brandice; Davis, Steven J. and Rodden, Jonathan. "Why Has US Policy Uncertainty Risen Since 1960?" American Economic Review, 2014, 104(5), pp. 56-60; https://doi.org/10.1257/aer.104.5.56.

Boxell, Levi; Gentzkow, Matthew and Shapiro, Jesse M. "Is the Internet Causing Political Polarization? Evidence from Demographics." Working paper, 2017.

DeBonis, Mike. "Trump Praises Spending Earmarks, and Capital Hill Again Erupts in Debate." Washington Post, January 9, 2018; https://www.washingtonpost.com/powerpost/trump-praises-spending-earmarks-and-capitol-hill-again-eruptsin-debate/2018/01/09/f6e950ba-f57b-11e7-b34a-b85626af34ef story.html?utm term=.48c83c0b6630.

Dimock, Michael; Doherty, Carroll; Kiley, Jocelyn and Oates, Russ. "Political Polarization in the American Public: How Increasing Ideological Uniformity and Partisan Antipathy Affect Politics, Compromise and Everyday Life." Pew Research Center, June 2014.

Gentzkow, Matthew; Shapiro, Jesse M. and Taddy, Matt. "Measuring Polarization in High-Dimensional Data: Method and Application to Congressional Speech." Working paper, 2017.

Grossman, Gene M. and Helpman, Elhanan. "Party Discipline and Pork-Barrel Politics.” Working paper, 2005.

Martin, Gregory J. and Yurukoglu, Ali. "Bias in Cable News: Persuasion and Polarization." American Economics Review, 2017, 107(9), pp. 2565-99; https://doi.org/10.1257/aer.20160812.

McCarty, Nolan. "Polarization, Congressional Dysfunction, and Constitutional Change." Indiana Law Review, 2016, 50.

Mian, Atif; Sufi, Amir and Trebbi, Francesco. "Resolving Debt Overhang: Political Constraints in the Aftermath of Financial Crises." American Economic Journal: Macroeconomics, 2014, 6(2), pp. 1-28; https://doi.org/10.1257/mac.6.2.1.

Pew Internet \& American Life Project. "Political Polarization in the American Public." Pew Research Center, June 12, 2014; http://www.people-press.org/2014/06/12/political-polarization-in-the-american-public/, accessed October 12, 2018.

Poole, Keith T. and Rosenthal, Howard. "The Polarization of American Politics." Journal of Politics, 1984, 46(4); https://doi.org/10.2307/2131242.

Shor, Boris and McCarty, Nolan. "The Ideological Mapping of American Legislatures." American Political Science Review, 2011, 105(3); https://doi.org/10.1017/S0003055411000153. 